\title{
Use of ozonated water as a new therapeutic approach to solve current concerns around antitumor treatment
}

\author{
KOHEI KURODA, MASAMITI YAMASHITA, YUSUKE MURAHATA, KAZUO AZUMA, TOMOHIRO OSAKI, \\ TAKESHI TSUKA, NORIHIKO ITO, TOMOHIRO IMAGAWA and YOSHIHARU OKAMOTO
}

Joint Department of Veterinary Clinical Medicine, Faculty of Agriculture, Tottori University, Tottori 680-8553, Japan

Received September 20, 2017; Accepted January 9, 2018

DOI: $10.3892 / e t m .2018 .6415$

\begin{abstract}
Tumor hypoxia is a severe problem affecting tumor therapy because it reduces the sensitivity of chemotherapy and radiation therapy. Ozone has been known to improve peripheral blood perfusion and oxygen partial pressure. The effect of ozonated water on tumor hypoxia, alone and in combination with an antitumor drug was studied in the present study. Following intraperitoneal administration of ozonated water to colon-26-bearing mice, the Hoechst 33342-positive area and the intratumoral oxygen partial pressure was significantly increased. The tumor growth rate was more suppressed when ozonated water was combined with cisplatin (CDDP) compared with CDDP treatment alone. The number of Ki-67-positive cells significantly decreased, whereas the number of TUNEL-positive cells significantly increased. The present study showed that ozonated water increased intratumoral blood perfusion and improved tumor hypoxia. In addition, ozonated water increased the therapeutic effect of CDDP. These findings, as well as previous reports, suggest that tumor growth is suppressed after treatment with ozonated water as the amount of CDDP reaching the tumor is increased when the intratumoral blood perfusion is increased due to the ozonated water. Thus, the administration of ozonated water may be a new therapeutic approach to solve current concerns regarding antitumor treatment.
\end{abstract}

\section{Introduction}

Ozone is an active form of oxygen, consisting of three oxygen atoms generated from diatomic oxygen by ultraviolet light and high voltage. Ozone gas is clear, colorless, and smells slightly like grass (1). Ozone therapy has been receiving increasing

Correspondence to: Professor Yoshiharu Okamoto, Joint Department of Veterinary Clinical Medicine, Faculty of Agriculture, Tottori University, 4-101 Koyama-Minami, Tottori 680-8553, Japan E-mail: yokamoto@muses.tottori-u.ac.jp

Key words: drug resistance, intratumoral oxygen partial pressure, intratumoral blood perfusion, cisplatin, ozonated water, tumor hypoxia attention in Europe and is known for its beneficial effects in reperfusion injury, infections, and cancer (2).

Ozonated water is the liquid form generated when ozone is dissolved in saline, which is much easier to handle than the gaseous form. The safety and direct antitumor effect of ozonated water have been previously described by us (3).

The primary form of ozone therapy is major autohemotherapy (MAH). In MAH, patient blood is mixed with ozone gas before being retransfused. It has been known for its beneficial effects in cardiovascular diseases, infections, cancer, rheumatoid arthritis, and osteoarthritis (4).

Ozone gas is known to improve peripheral blood perfusion. Ozone therapy in tumor patients improves intratumoral oxygen partial pressure (4). Tumor hypoxia is a serious concern affecting tumor therapy because it reduces the sensitivity of chemotherapy and radiation therapy (5-8). Therefore, it is expected to improve the sensitivity of antitumor therapy. In clinical settings, the combination of radiation therapy and MAH or rectal administration of ozone gas/oxygen gas mixture has helped achieve the same effects as those obtained by using a combination of radiation therapy and chemotherapy in preventing the progression of head and neck cancer (9). Reports related to chemotherapy mostly discuss side effects; few reports discuss therapeutic effects (10-12). To the best of our knowledge, no other study has discussed ozone therapy using ozonated water. Therefore, a new approach using ozonated water was examined to solve concerns around antitumor treatment. In this report, we decided to study the effect of ozonated water on tumor hypoxia, alone and in combination with an antitumor drug.

\section{Materials and methods}

Preparation of ozonated water. The device producing ozonated water was provided by Sakuragawa Pump Co., Ltd., (Osaka, Japan). This device can produce ozonated water from $\mathrm{O}_{2}$ and water and can regulate the concentration of dissolved ozone. In all experiments, the concentration of ozonated water was $208 \mu \mathrm{M}$ and it was administered within $10 \mathrm{~min}$ of production.

Animals. BALB/c mice (4 to 5-week-old, female) were purchased from CLEA Japan, Inc. (Osaka, Japan). All mice were maintained under conventional conditions. The study was performed according to the rules put down by the Tottori 
University. The use of these animals and the procedures undertaken was approved by the Animal Research Committee of Tottori University. All treatments were performed under anesthesia, induced by the inhalation of 3-5\% isoflurane; all efforts were made to minimize suffering.

Preparation of the tumor-bearing mouse model. The mouse cell line derived from the Colon 26 (RCB2657), the mouse colorectal cancer model, was obtained from the RIKEN BioResource Center (BRC) through the National Bio-Resource Project of the MEXT (Ibaraki, Japan). The tumor-bearing mouse model was prepared as described previously, with slight modification (13). In brief, $1 \times 10^{6}$ cells $\left(1 \times 10^{7}\right.$ cells $\left./ \mathrm{ml}\right)$ were subcutaneously injected into the dorsal region of BALB/c mice. Mice whose tumors grew to a diameter of 7-10 $\mathrm{mm}$ were included in the study.

Measurement of intratumoral oxygen partial pressure. Mice were randomized into two groups: Sterile saline (S) group and ozonated water $\left(\mathrm{O}_{3}\right)$ group ( $\mathrm{n}=5$ per group). Oxygen and indifferent electrodes (Bio Research Co., Nagoya, Japan) were inserted into the center of the tumor. After intraperitoneal administration of sterile saline or ozonated water $(0.2 \mathrm{ml} / \mathrm{head})$, intratumoral oxygen partial pressure was measured by polarography (Bio Research Co.), every $10 \mathrm{~min}$ immediately after administration up to $150 \mathrm{~min}$.

Measurement of blood gas. Blood samples were collected after administration of sterile saline or ozonated water, and blood gas was measured using at $0,10,30,60$, and $120 \mathrm{~min}$ after administration.

Evaluation of intratumoral blood perfusion. Eighty min after administration of sterile saline or ozonated water, $30 \mathrm{mg} / \mathrm{kg}$ Hoechst 33342 (H33342) dissolved in phosphate-buffered saline (PBS) was administrated intravenously. After $4 \mathrm{~min}$, the mice were euthanized by cervical dislocation under anesthesia induced by the inhalation of 3-5\% isoflurane. The tumors were embedded in an optimal cutting temperature (OCT) compound. The cryostat sections $(10 \mathrm{~mm})$ were fixed in acetone for $5 \mathrm{~min}$ at $4^{\circ} \mathrm{C}$. These sections were analyzed by fluorescence microscopy. The percentage of positive areas in the tumor tissues was calculated by dividing the total pixel area of the positive areas by the total pixel area corresponding to the entire tumor tissue in the field of view. The mean scores for 25 fields were used as the percentages of positive areas per group.

Effect of ozonated water and cisplatin (CDDP) in combination, on colon-26 mice. For this experiment, the mice were randomized into six groups ( $n=8$ per group): Sterile saline $(\mathrm{S})$ group, ozonated water $\left(\mathrm{O}_{3}\right)$ group, sterile saline and $5.0 \mathrm{mg} / \mathrm{kg}$ CDDP group (S-CDDP5.0), ozonated water and $5.0 \mathrm{mg} / \mathrm{kg}$ CDDP group ( ${ }_{3}$-CDDP5.0), ozonated water and $3.4 \mathrm{mg} / \mathrm{kg} \mathrm{CDDP}$ group $\left(\mathrm{O}_{3}-\mathrm{CDDP} 3.4\right)$, and ozonated water and $1.7 \mathrm{mg} / \mathrm{kg}$ CDDP group $\left(\mathrm{O}_{3}-\mathrm{CDDP} 1.7\right)$. The volume of these tumor tissues was calculated as follows: (mediastinum $\mathrm{x}$ transverse line $\mathrm{x}$ depth $\mathrm{x} \pi) / 6\left(\mathrm{~mm}^{3}\right)$. Then, CDDP $(5.0,3.4,1.7 \mathrm{mg} / \mathrm{kg})$ and saline or ozonated water $(0.2 \mathrm{ml} / \mathrm{head})$ were intraperitoneally administered to the S-CDDP5.0, $\mathrm{O}_{3}$-CDDP5.0, $\mathrm{O}_{3}$-CDDP3.4, and $\mathrm{O}_{3}$-CDDP1.7 groups. In the $\mathrm{S}$ and $\mathrm{O}_{3}$ groups, only sterile saline or ozonated water was administered. On day 7, the volumes of the tumor tissues were calculated and the mice were euthanized by cervical dislocation under anesthesia as described before. Based on the tumor volumes on days 1 and 7 , the tumor growth rates were calculated as follows: (tumor volume on day 7-tumor volume on day 1$) / 7$ ( $\mathrm{mm}^{3} /$ day). The tumors were fixed in $10 \%$ buffered formalin.

Ki-67 staining. Tissue sections $(3 \mu \mathrm{m})$ obtained on glass slides were deparaffinized, washed with ethanol and water, and soaked in PBS. The sections were autoclaved with $0.01 \mathrm{M}$ citrate buffer ( $\mathrm{pH}$ 6.0) for $15 \mathrm{~min}\left(121^{\circ} \mathrm{C}\right)$. The sections were then washed with PBS and incubated with the rabbit polyclonal anti-Ki-67 antibody (1:50; E0468; Dako, Glostrup, Denmark) for $30 \mathrm{~min}$ at room temperature. After washing with PBS, the sections were incubated with rat anti-IgG antibody (1:100; sc-372; Vector Laboratories, Inc., Burlingame, CA, USA) for $30 \mathrm{~min}$ at room temperature. The slides were washed with PBS and stained using the ABC method (PK-4000; Vector Laboratories, Inc.) for $30 \mathrm{~min}$. Cell counts in 25 random fields were calculated at a magnification, $\mathrm{x} 400$ by using five mice from each group.

TUNEL staining. Tissue sections ( $3 \mu \mathrm{m})$ obtained on glass slides were deparaffinized, washed with ethanol and water, and soaked in diluted water. TUNEL staining was performed using the in-situ Apoptosis Detection kit (Takara Bio, Inc., Shiga, Japan), according to the manufacturer's instructions. Cell counts were calculated as described in the previous subsection.

Statistical analysis. Data are expressed as the mean \pm standard (SD) or standard error (SE). Statistical analyses were first performed using F-test or analysis of variance (ANOVA) and compared using the Student's t-test or Tukey-Kramer test. $\mathrm{P}<0.05$ or 0.01 indicated statistical significance.

\section{Results}

Effect on blood gas and intratumoral oxygen partial pressure. Before and after the administration of $\mathrm{O}_{3}$ or sterile saline, no apparent change was noted in the blood gas levels (Table I). No significant difference was noted between the $\mathrm{O}_{3}$ and $\mathrm{S}$ groups.

In the $S$ group, there was no apparent change in the intratumoral oxygen partial pressure. However, the partial pressure in the $\mathrm{O}_{3}$ group significantly increased compared to that in the $\mathrm{S}$ group at 20 min after administration (Fig. 1). It peaked at 50 min after administration and gradually decreased afterward. At 130 min after administration, no significant difference was noted between the $\mathrm{O}_{3}$ and $\mathrm{S}$ groups.

Effect on intratumoral blood perfusion. The intratumoral blood perfusion in the $\mathrm{O}_{3}$ group increased compared to that in the $\mathrm{S}$ group (Fig. 2). The H33342-positive area was $12.3 \pm 3.2 \%$ in the $\mathrm{S}$ group and $25.6 \pm 4.6 \%$ in the $\mathrm{O}_{3}$ group. There was a significant difference between the two groups $(\mathrm{P}<0.05)$.

Effect of ozonated water and CDDP in combination. Tumor growth was significantly suppressed in the $\mathrm{O}_{3}$-CDDP5.0 group 
Table I. Effect of ozonated water on blood gas.

A, Effect in $\mathrm{O}_{3}$ group

\begin{tabular}{|c|c|c|c|c|c|}
\hline Time (min) & $\mathrm{pH}$ & $\mathrm{pCO}_{2}(\mathrm{mmHg})$ & $\mathrm{pO}_{2}(\mathrm{mmHg})$ & $\mathrm{HCO}_{3}(\mathrm{mmol} / \mathrm{l})$ & $\mathrm{sO}_{2}(\%)$ \\
\hline 0 & $7.335 \pm 0.03$ & $38.9 \pm 4.5$ & $56 \pm 4.7$ & $20.7 \pm 1.2$ & $87 \pm 4.6$ \\
\hline 10 & $7.276 \pm 0.04$ & $38.6 \pm 4.9$ & $53 \pm 4.3$ & $20 \pm 0.6$ & $85 \pm 4.8$ \\
\hline 30 & $7.277 \pm 0.03$ & $38.1 \pm 5.0$ & $59 \pm 5.2$ & $19 \pm 1.0$ & $87 \pm 5.8$ \\
\hline 60 & $7.339 \pm 0.02$ & $36.9 \pm 4.3$ & $54 \pm 4.6$ & $21 \pm 0.8$ & $86 \pm 3.8$ \\
\hline 120 & $7.323 \pm 0.03$ & $42.4 \pm 4.5$ & $64 \pm 4.8$ & $23 \pm 1.3$ & $90 \pm 5.2$ \\
\hline
\end{tabular}

$\mathrm{B}$, Effect in $\mathrm{S}$ group

\begin{tabular}{|c|c|c|c|c|c|}
\hline Time (min) & $\mathrm{pH}$ & $\mathrm{pCO}_{2}(\mathrm{mmHg})$ & $\mathrm{pO}_{2}(\mathrm{mmHg})$ & $\mathrm{HCO}_{3}(\mathrm{mmol} / \mathrm{l})$ & $\mathrm{sO}_{2}(\%)$ \\
\hline 0 & $7.347 \pm 0.03$ & $39.2 \pm 6.7$ & $57.3 \pm 5.4$ & $19.6 \pm 1.3$ & $83 \pm 3.9$ \\
\hline 10 & $7.336 \pm 0.02$ & $39.7 \pm 3.7$ & $46 \pm 6.3$ & $19.9 \pm 0.5$ & $78.6 \pm 5.3$ \\
\hline 30 & $7.324 \pm 0.04$ & $39.3 \pm 4.3$ & $55 \pm 4.6$ & $20.5 \pm 0.7$ & $86 \pm 4.6$ \\
\hline 60 & $7.382 \pm 0.03$ & $35.2 \pm 5.4$ & $51 \pm 4.2$ & $20.5 \pm 0.6$ & $85 \pm 5.3$ \\
\hline 120 & $7.229 \pm 0.02$ & $47.9 \pm 4.4$ & $58 \pm 4.2$ & $23.5 \pm 0.8$ & $87 \pm 4.9$ \\
\hline
\end{tabular}

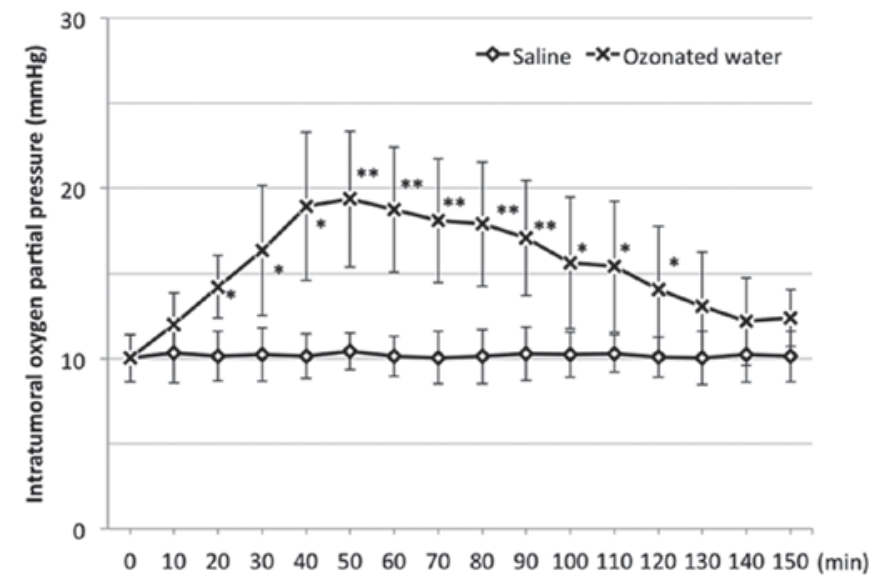

Figure 1. Effect of ozonated water on the intratumoral oxygen partial pressure. This graph shows the change in the intratumoral oxygen partial pressure after intraperitoneal administration of ozonated water or saline. 'Diamond' indicates the group administered sterile saline (S) and 'cKross' indicates the group administered ozonated water $\left(\mathrm{O}_{3}\right)$. Data are shown as the mean \pm standard deviation. ${ }^{*} \mathrm{P}<0.05$ or ${ }^{* *} \mathrm{P}<0.01$ vs. saline (obtained by using t-test) indicates significant difference.

compared to that in the $\mathrm{S}$ and $\mathrm{O}_{3}$ groups $(\mathrm{P}<0.05)$ (Fig. 3). A statistically significant difference was not observed between the S-CDDP5.0 and $\mathrm{O}_{3}$-CDDP5.0 groups. However, tumor growth in the $\mathrm{O}_{3}$-CDDP5.0 group tended to be suppressed, compared to that in the S-CDDP5.0 group. In the $\mathrm{O}_{3}-\mathrm{CDDP} 3.4$ group, despite reducing the concentration of the antitumor drug, tumor growth suppression was observed, which was comparable to that observed in the S-CDDP group.

In the $\mathrm{O}_{3}$-CDDP5.0 group, the number of $\mathrm{Ki}$-67-positive cells significantly decreased, compared to that in the other groups (Fig. 4). The number of Ki-67-positive cells in the $\mathrm{O}_{3}$-CDDP3.4 and S-CDDP groups significantly decreased, compared to that in the $\mathrm{S}, \mathrm{O}_{3}$, and $\mathrm{O}_{3}$-CDDP1.7 groups.
There was no statistically significant difference between the S-CDDP5.0 and $\mathrm{O}_{3}$-CDDP3.4 groups.

In the $\mathrm{O}_{3}$-CDDP5.0 group, the number of TUNEL-positive cells significantly increased, compared to that of the other groups (Fig. 5). The number of TUNEL-positive cells in the $\mathrm{O}_{3}$-CDDP3.4 group significantly increased, compared to that in the $\mathrm{S}$ and $\mathrm{O}_{3}$ groups. No statistically significant difference was observed among the S-CDDP5.0, $\mathrm{O}_{3}-\mathrm{CDDP} 3.4$, and $\mathrm{O}_{3}$-CDDP1.7 groups.

\section{Discussion}

In the present study, the intratumoral blood perfusion was found to have increased and the intratumoral oxygen partial pressure was found to have improved after intraperitoneal administration of ozonated water. To the best of our knowledge, such effects of ozonated water have not been reported thus far. Further, when ozonated water was used in combination with CDDP, the antitumor effect of CDDP was enhanced. Most studies related to chemotherapy discuss side effects; very few reports discuss therapeutic effects (10-12). The findings of this study can be considered extremely important evidence with respect to the use of ozonated water.

When the ozonated water was intraperitoneally administered, no apparent change was noted in the blood gas levels. However, the intratumoral oxygen partial pressure significantly increased. These results indicate that ozonated water increases intratumoral oxygen partial pressure without affecting blood gas levels. Ozone gas is known to improve peripheral blood perfusion owing to its vasodilating effect $(14,15)$. When the extent of intratumoral blood perfusion was evaluated by $\mathrm{H} 33342$, a significant increase was noted in the $\mathrm{O}_{3}$ group. Tumor hypoxia generally progresses because of reduction in the intratumoral blood perfusion caused by an imbalance between the tumor growth rate and tumor blood 

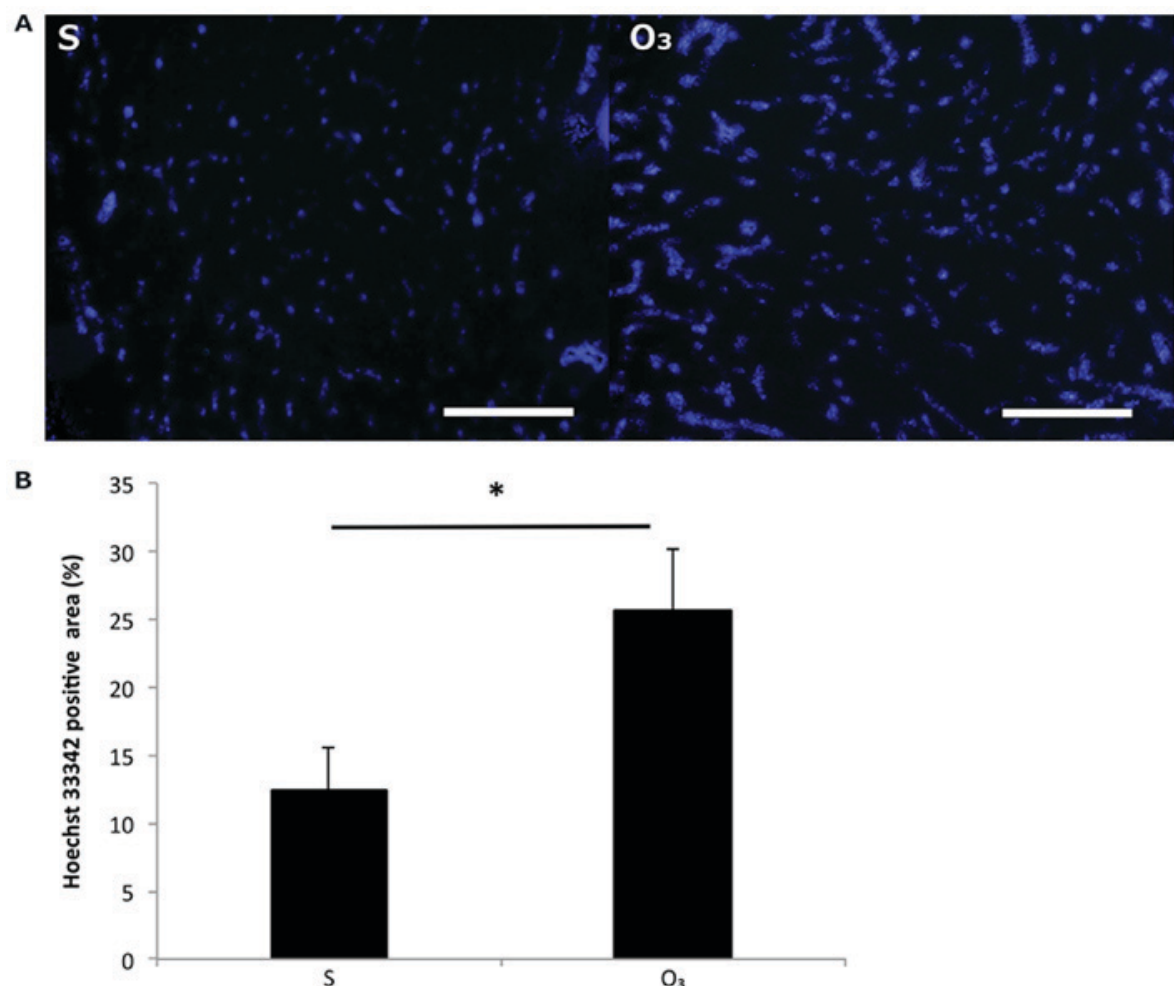

Figure 2. Effect of ozonated water on intratumoral blood perfusion. (A) H33342-positive area in each group: sterile saline $(\mathrm{S})$ and ozonated water $\left(\mathrm{O}_{3}\right)$ groups Scale bar: $50 \mu \mathrm{m}$. (B) Quantitative value of the H33342-positive area. Data are shown as the mean \pm standard deviation. " $\mathrm{P}<0.05$ as indicated, obtained by using t-test, indicates significant difference.

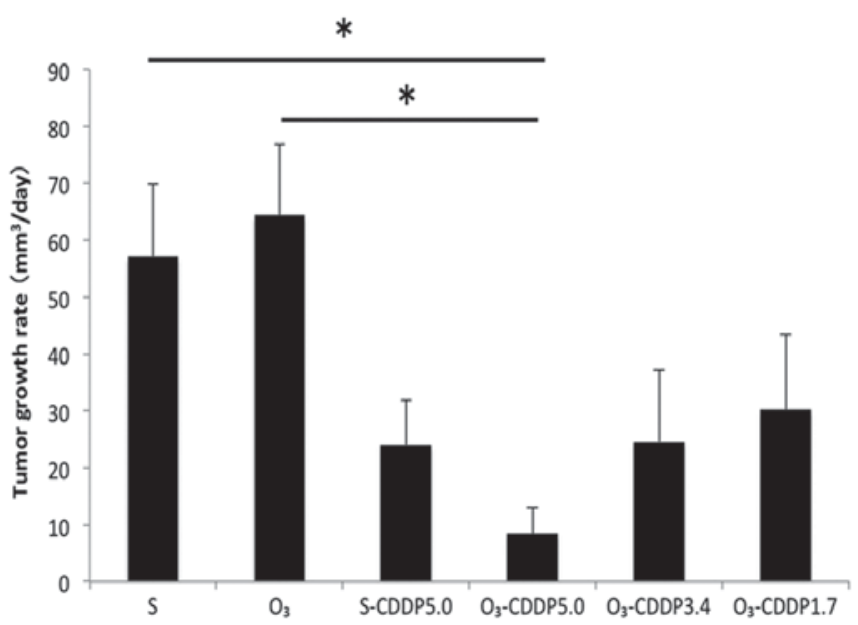

Figure 3. Effect combining ozonated water with CDDP on tumor growth rate. The graph shows the tumor growth rate for each group: Sterile saline administration (S) group, and ozonated water administration $\left(\mathrm{O}_{3}\right)$ group, administration of sterile saline and $5.0 \mathrm{mg} / \mathrm{kg}$ CDDP group (S-CDDP5.0), administration of ozonated water and $5.0 \mathrm{mg} / \mathrm{kg}$ CDDP group $\left(\mathrm{O}_{3}\right.$-CDDP5.0), administration of ozonated water and $3.4 \mathrm{mg} / \mathrm{kg}$ CDDP group $\left(\mathrm{O}_{3}\right.$-CDDP3.4), administration of ozonated water and $1.7 \mathrm{mg} / \mathrm{kg} \mathrm{CDDP}$ group $\left(\mathrm{O}_{3}-\mathrm{CDDP} 1.7\right)$. The data show the mean \pm standard error. Significant differences are shown by ${ }^{*} \mathrm{P}<0.05$ as indicated using Tukey-Kramer test.

vessel formation rate $(16,17)$. This result indicates that ozonated water as well as ozone gas increase peripheral blood perfusion. In addition, it indicated that the increase in the intratumoral oxygen partial pressure might be due to the increase in intratumoral blood perfusion. Oxidation as well as activation of antioxidant enzymes are caused by the administration of ozone. When active oxygen is removed by superoxide dismutase (SOD), hydrogen peroxide $\left(\mathrm{H}_{2} \mathrm{O}_{2}\right)$ is produced. $\mathrm{H}_{2} \mathrm{O}_{2}$ is involved in vasodilation as an endothelium-derived hyperpolarizing factor (EDHF), one of the endothelium-derived vasorelaxation factors (18). Therefore, it has been thought that ozone extends the peripheral vessels by means of $\mathrm{H}_{2} \mathrm{O}_{2}$ and increases peripheral blood perfusion (14). Ozonated water is likely to increase blood perfusion by a similar mechanism. However, the underlying mechanism needs to be studied further. In addition, the changes in peripheral blood perfusion in normal tissues warrant further study.

Tumor hypoxia is a serious problem for tumor treatment because it reduces the sensitivity to chemical, radiation, and photodynamic therapy $(5-8,16)$. The reasons for resistance to chemotherapy include cell cycle arrest $(19,20)$, acquisition of antiapoptotic activity by inhibition of apoptosis-inducing proteins such as Bid and Bax $(21,22)$, and reduction in the amount of drug reaching the tumor because of decreased blood flow (8).

The rate of tumor growth in the $\mathrm{O}_{3}$-CDDP5.0 group tended to decrease compared to that in the S-CDDP5.0 group. In addition, the number of Ki-67-positive cells significantly decreased and the number of TUNEL-positive cells significantly increased in the $\mathrm{O}_{3}$-CDDP5.0 group compared to that in the S-CDDP5.0 group. CDDP exerts an antitumor effect by inducing apoptosis and suppressing tumor growth by inhibiting deoxyribonucleic acid (DNA) synthesis (23). Therefore, the results of Ki-67 and TUNEL staining suggested that the effect of CDDP was enhanced by the administration of ozonated water. The antitumor effect of CDDP depends on the amount of CDDP reaching the site of tumor rather 


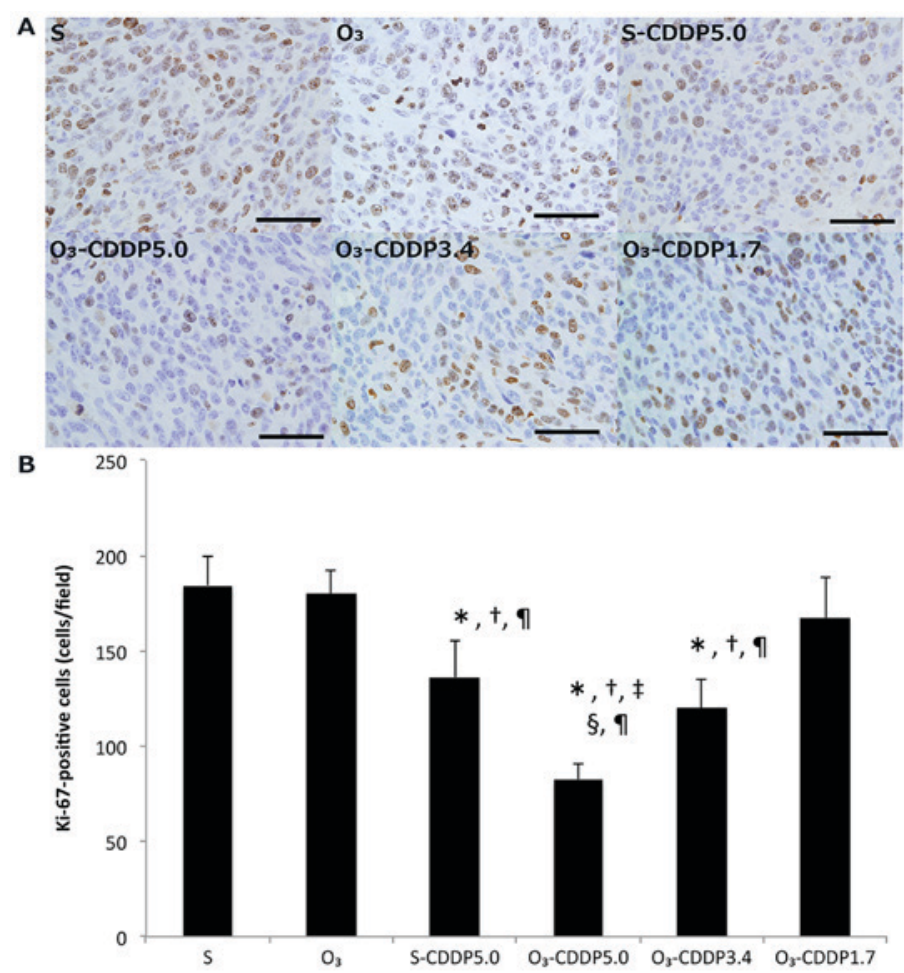

Figure 4. The effect combining ozonated water with CDDP in Ki-67 staining. (A) The graph image shows the Ki-67 positive area for each group: Sterile saline administration (S) group, and ozonated water administration $\left(\mathrm{O}_{3}\right)$ group, administration of sterile saline and $5.0 \mathrm{mg} / \mathrm{kg}$ CDDP group (S-CDDP5.0), administration of ozonated water and $5.0 \mathrm{mg} / \mathrm{kg}$ CDDP group $\left(\mathrm{O}_{3}\right.$-CDDP5.0), administration of ozonated water and $3.4 \mathrm{mg} / \mathrm{kg}$ CDDP group $\left(\mathrm{O}_{3}\right.$-CDDP3.4), administration of ozonated water and $1.7 \mathrm{mg} / \mathrm{kg}$ CDDP group ( $\mathrm{O}_{3}$-CDDP1.7). Scale bar, $500 \mu \mathrm{m}$. (B) The graph shows the number of the Ki-67 positive cells. The data show the mean \pm standard error. Significant differences are shown by $\mathrm{P}<0.01$ (" $\mathrm{P}<0.01$ vs. $\mathrm{S}$; ${ }^{\mathrm{P}} \mathrm{P}<0.01$ vs. $\mathrm{O}_{3}$; ${ }^{*} \mathrm{P}<0.01$ vs. S-CDDP5.0; ${ }^{{ }^{*}} \mathrm{P}<0.01$ vs. $\mathrm{O}_{3}$-CDDP3.4; ${ }^{5} \mathrm{P}<0.01$ vs. $\mathrm{O}_{3}$-CDDP1.7) using Tukey-Kramer test.

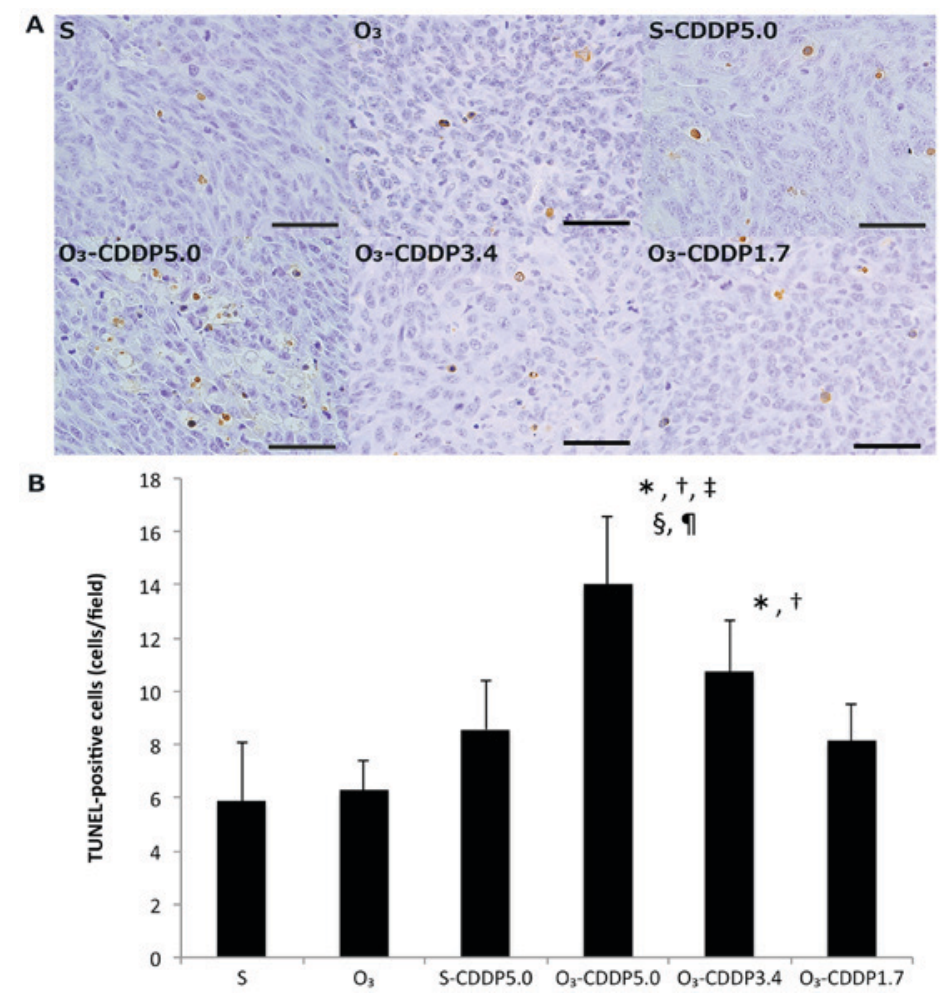

Figure 5. The effect combining ozonated water with CDDP in TUNEL stainig. (A) The images show the TUNEL positive area for each group: Sterile saline administration ( $\mathrm{S}$ ) group, and ozonated water administration $\left(\mathrm{O}_{3}\right)$ group, administration of sterile saline and $5.0 \mathrm{mg} / \mathrm{kg}$ CDDP group (S-CDDP5.0), administration of ozonated water and $5.0 \mathrm{mg} / \mathrm{kg}$ CDDP group $\left(\mathrm{O}_{3}\right.$-CDDP5.0), administration of ozonated water and $3.4 \mathrm{mg} / \mathrm{kg}$ CDDP group $\left(\mathrm{O}_{3}\right.$-CDDP3.4), administration of ozonated water and $1.7 \mathrm{mg} / \mathrm{kg}$ CDDP group $\left(\mathrm{O}_{3}\right.$-CDDP1.7). Scale bar, $500 \mu \mathrm{m}$. (B) The graph shows the number of the TUNEL positive cells. The data show the mean \pm standard error. Significant differences are shown by $\mathrm{P}<0.01$ ("P $<0.01$ vs. $\mathrm{S} ;{ }^{\circ} \mathrm{P}<0.01$ vs. $\mathrm{O}_{3} ;{ }^{\circ} \mathrm{P}<0.01$ vs. S-CDDP5.0; ${ }^{\text {" }} \mathrm{P}<0.01$ vs. $\mathrm{O}_{3}-\mathrm{CDDP} 1.7$ ) or $\mathrm{P}<0.05$ ( ${ }^{\$} \mathrm{P}<0.05$ vs. $\left.\mathrm{O}_{3}-\mathrm{CDDP} 3.4\right)$ using Tukey-Kramer test. 
than the proliferation activity of tumor cells $(24,25)$. These findings as well as previous reports suggest that tumor growth is suppressed on treatment with ozonated water because the amount of CDDP reaching the tumor is increased when the intratumoral blood perfusion is increased because of ozonated water. We plan to measure the concentration of intratumoral antitumor drug in the future and investigate in detail.

In recent years, it has been reported that the inhibition of apoptosis-inducing protein is associated with resistance to platinum-based drug preparations (21). However, it is unknown whether those proteins are involved in the resistance mechanism. It might not affect protein expression because the increase in oxygen partial pressure observed in this study occurred only $2 \mathrm{~h}$ after the administration of ozonated water. In order to clarify the mechanism, the genes and proteins related to hypoxia and apoptosis need to be studied further.

The $\mathrm{O}_{3}$-CDDP5.0 group showed tumor growth suppression, to almost the same extent as that observed in the S-CDDP5.0 group. This suggests that it is possible to reduce the required drug concentration, while maintaining the antitumor effect, by using ozonated water and general chemotherapy in combination. We intend to conduct detailed studies on other drugs and tumor types in the future.

The present study showed that ozonated water increases intratumoral blood perfusion and improves intratumoral oxygen partial pressure. In addition, tumor growth was more suppressed when ozonated water and CDDP therapy were combined. Thus, the administration of ozonated water could be a new approach to solve current concerns around antitumor treatment, such as tumor hypoxia and drug resistance of tumors.

\section{References}

1. Viebahn-Haensler R and Lee A (eds): The Use of Ozone in Medicine. 5th edition. ODREI-Publishers, Iffezheim, p148, 2007.

2. Nogales CG, Ferrari PH, Kantorovich EO and Lage-Marques JL: Ozone therapy in medicine and dentistry. J Contemp Dent Pract 9: 75-84, 2008.

3. Kuroda K, Azuma K, Mori T, Kawamoto K, Murahata Y, Tsuka T, Osaki T, Ito N, Imagawa T, Itoh F and Okamoto Y: The safety and anti-tumor effects of ozonated water in vivo. Int J Mol Sci 16: 25108-25120, 2015.

4. Clavo B, Pérez JL, López L, Suárez G, Lloret M, Rodríguez V, Macías D, Santana M, Hernández MA, Martín-Oliva R and Robaina F: Ozone therapy for tumor oxygenation: A pilot study. Evid Based Complement Alternat Med 1: 93-98, 2004.

5. Graeber TG, Osmanian C, Jacks T, Housman DE, Koch CJ, Lowe SW and Giaccia AJ: Hypoxia-mediated selection of cells with diminished apoptotic potential in solid tumours. Nature 379: 88-91, 1996.

6. Bertout JA, Patel SA and Simon MC: The impact of $\mathrm{O}_{2}$ availability on human cancer. Nat Rev Cancer 8: 967-975, 2008.

7. Semenza GL: Targeting HIF-1 for cancer therapy. Nat Rev Cancer 3: 721-732, 2003.

8. Teicher BA: Hypoxia and drug resistance. Cancer Metastasis Rev 13: 139-168, 1994.

9. Clavo B, Ruiz A, Lloret M, López L, Suárez G, Macías D, Rodríguez V, Hernández MA, Martín-Oliva R, Quintero S, et al: Adjuvant ozonetherapy in advanced head and neck tumors: A comparative study. Evid Based Complement Alternat Med 1: 321-325, 2004.
10. Borrego A, Zamora ZB, González R, Romay C, Menéndez S, Hernández F, Montero T and Rojas E: Protection by ozone preconditioning is mediated by the antioxidant system in cisplatin-induced nephrotoxicity in rats. Mediators Inflamm 13: 13-19, 2004.

11. Borrego A, Zamora ZB, González R, Romay C, Menéndez S, Hernández F, Berlanga $\mathrm{J}$ and Montero T: Ozone/oxygen mixture modifies the subcellular redistribution of bax protein in renal tissue from rats treated with cisplatin. Arch Med Res 37: 717-722, 2006.

12. González R, Borrego A, Zamora Z, Romay C, Hernández F, Menéndez S, Montero T and Rojas E: Reversion by ozone treatment of acute nephrotoxicity induced by cisplatin in rats. Mediators Inflamm 13: 307-312, 2004.

13. Nitta M, Azuma K, Hata K, Takahashi S, Ogiwara K, Tsuka T, Imagawa T, Yokoe I, Osaki T, Minami S and Okamoto Y: Systemic and local injections of lupeol inhibit tumor growth in a melanoma-bearing mouse model. Biomed Rep 1: 641-645, 2013.

14. Mukhina IV, Dudina EV, Yakovleva EI, Zhemarina NV, Prodanecs NN, Evdokimova OS, Manuhina EB and Dvornikov AV: The dose-dependent effect of ozonated physiological solution on arterial vasodilation. IOA 17th World Ozone Congress-Strasbourg 2005 III.3.9-1, 2005.

15. Dutka M, Adamczak M, Kopieczna-Grzebieniak E, Grabowska-Bochenek R and Wesolowski W: Vasorelaxant activity of ozone-in vitro studies. Adv Clin Exp Med 4: 391-398, 1998.

16. Brown JM and Wilson WR: Exploiting tumour hypoxia in cancer treatment. Nat Rev Cancer 4: 437-447, 2004.

17. Lunt SJ, Chaudary N and Hill RP: The tumor microenvironment and metastatic disease. Clin Exp Metastasis 26: 19-34, 2009.

18. Takaki A, Morikawa K, Tsutsui M, Murayama Y, Tekes E, Yamagishi H, Ohashi J, Yada T, Yanagihara N and Shimokawa H: Crucial role of nitric oxide synthases system in endothelium-dependent hyperpolarization in mice. J Exp Med 205: 2053-2063, 2008.

19. Amellem O, Löffler M and Pettersen EO: Regulation of cell proliferation under extreme and moderate hypoxia: The role of pyrimidine (deoxy)nucleotides. Br J Cancer 70: 857-866, 1994.

20. Gardner LB, Li Q, Park MS, Flanagan WM, Semenza GL and Dang CV: Hypoxia inhibits G1/S transition through regulation of p27 expression. J Biol Chem 276: 7919-7926, 2001.

21. Erler JT, Cawthorne CJ, Williams KJ, Koritzinsky M, Wouters BG, Wilson C, Miller C, Demonacos C, Stratford IJ and Dive C: Hypoxia-mediated down-regulation of Bid and Bax in tumors occurs via hypoxia-inducible factor 1-dependent and -independent mechanisms and contributes to drug resistance. Mol Cell Biol 24: 2875-2889, 2004.

22. Mayes PA, Dolloff NG, Daniel CJ, Liu JJ, Hart LS, Kuribayashi K, Allen JE, Jee DI, Dorsey JF, Liu YY, et al: Overcoming hypoxia-induced apoptotic resistance through combinatorial inhibition of GSK-3 $\beta$ and CDK1. Cancer Res 71: 5265-5275, 2011.

23. Kartalou M and Essigmann JM: Mechanisms of resistance to cisplatin. Mutat Res 478: 23-43, 2001.

24. Takahashi K: The effect of cis-Dichlorodiammineplatinum (II) on tumor growth and progress in the cell cycle. Japanese Journal of Cancer and Chemotherapy 9: 624-631, 1982 (In Japanese).

25. Drewinko B, Brown BW and Gottlieb JA: The effect of cis-diamminedichloroplatinum (II) on cultured human lymphoma cells and its therapeutic implications. Cancer Res 33: 3091-3095, 1973.

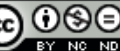

This work is licensed under a Creative Commons Attribution-NonCommercial-NoDerivatives 4.0 International (CC BY-NC-ND 4.0) License. 